\title{
PELATIHAN KEAMANAN SISTEM INSTALASI KABEL TANAM DI DESA MELINGGIH KECAMATAN PAYANGAN-GIANYAR
}

\author{
I.N. Budiastra ${ }^{1}$, C.G.I. Partha ${ }^{2}$, I.G.D. Arjana ${ }^{3}$ dan I.B.A. Swamardika ${ }^{4}$
}

\begin{abstract}
ABSTRAK
Listrik merupakan kebutuhan yang sangat vital bagi kehidupan masyarakat sekarang ini. Listrik menjadi kebutuhan primer karena selain harganya relatif murah juga sangat membantu dalam kehidupan sehari-hari. Selain listrik mempunyai keuntungan yang sangat besar, listrik juga mempunyai bahaya yang dapat mengakibatkan kecelakaan seperti tersengat arus listrik, kebakaran dan kerusakan peralatan listrik.

Bali merupakan pulau Dewata dan daerah kunjungan Pariwisata yang sangat terkenal baik lokal maupun Internasional. Keindahan pulau Bali harus kita jaga bersama agar tampak lebih alami. Penerangan merupakan salah satu efek sinar yang membuat keindahan menjadi tampak lebih alami. Penempatan lampulampu sebagai penerangan untuk menciptakan suasana yang alami, biasanya ditempatkan di atas atau di bawah, karena sinar yang mengenai objek tidak terganggu. Karena Permasalahn di atas, maka instalasi listrik juga menjadi hal yang sangat berpengaruh bagi estetika, sehingga instalasi tersebut umumnya ditanan di dalam tanah. Kendala utama dalam sistem dalam tanah adalah cara memasang dan mengamankan penghantar tersebut. Dari permasalahan tersebut pengabdian ini akan memberikan informasi tentang keamanan sistem instalasi kabel tanam. Bahaya listrik dapat dihilangkan dengan mengikuti semua persyaratan-persyaratan instalasi listrik. Bahaya sengatan listrik dan kebakaran dapat di atasi dengan pengaman instalasi listrik yang tertuang dalam Persyaratan Umum Instalasi Listrik 2011 (PUIL 2011serta Amandemen tahun 2014, yang mengisyaratkan untuk mengamankan lingkungan dalam hal ini mengamankan manusia, wajib menggunakan pengaman instalasi listrik sesuai pengaman dengan Standar Nasional Indonesia (SNI). Dalam pengabdian ini diberikan penjelasan dan Pelatihan Keamanan Sistem Instalasi Kabel Tanam Di Desa Melinggih Kecamatan Payangan-Gianyar, yang mana dilokasi pengabdian sering terjadi gangguan sistem kelistrikan karena pemasangan kabel dan peralatan yang tidak memenuhi persyaratan instalasi listrik.
\end{abstract}

Kata Kunci : Listrik, Keamanan, Kabel Tanam, Estetika, Pengabdian

\begin{abstract}
Electricity is a very vital needs for the life of the community it is today. Electricity became the primary needs of the relatively inexpensive price because in addition is also very helpful in everyday life. In addition to electricity has huge advantages, electricity also has a hazard that can lead to accidents such as fire, electrical current was stung and damage electrical equipment. Bali is an island of the gods and the visit of a very famous Tourism both locally and internationally. The beauty of Bali we must keep together in order to look more natural. Lighting is one of the effects of the sun rays create the beauty of being a more natural look. The placement of the lights as the lighting to create a natural atmosphere, usually placed on top of or below, because the light on the object is not interrupted. Because of the Permasalahn above, then the electrical installation has also become very influential for aesthetics, so the installation is generally ditanan in the ground. The main constraint in the system in the ground is a way to install and secure the conductor. Of these

\footnotetext{
${ }^{1}$ Staf Pengajar Jurusan Teknik Elektro Fakultas Teknik Universitas Udayana, nyomanbudiastra@unud.ac.id.

${ }^{2}$ Staf Pengajar Jurusan Teknik Elektro Fakultas Teknik Universitas Udayana, cokindra@unud.ac.id

${ }^{3}$ Staf Pengajar Jurusan Teknik Elektro Fakultas Teknik Universitas Udayana, dyanaarjana@unud.ac.id

${ }^{4}$ Staf Pengajar Jurusan Teknik Elektro Fakultas Teknik Universitas Udayana, gusalit@unud.ac.id
} 
problems this devotion will provide information about the security system wiring installation. Electrical hazards can be eliminated by following all electrical installation requirements. Danger of electric shock and fires can be corrected with electrical installation safety contained in the 2011 electrical installation General requirements (Amendment 2011serta year 2014 PUIL, who hinted to secure the environment in this securing human safety, mandatory use of electrical installation in accordance with the National Standard safety Indonesia (SNI). In this devotion will be given explanations and Training Security System Installation Cable plant in the village of Payangan Gianyar-Melinggih Sub-district, which provide devotion often occur because of electrical interference system wiring and equipment who do not meet the requirements of the electrical installation.

Keywords: Electric, Security, Cable Plant, Aesthetics, devotion

\section{PENDAhUluaN}

Kecamatan Payangan kabupaten Gianyar, dimana kecamatan ini memiliki hawa yang sejuk bahkan cenderung dingin dan dikenal sebagai daerah yang subur dan cocok untuk lahan pertanian dan agro wisata. Pada saat sekarang kecamatan ini mulai tumbuh menjadi kota pariwisata. Desa Melinggih merupakan salah satu desa di kecamatan payangan dan merupakan pusat kota kecamatan dengan berbagi aktifitas. Bertambahnya jumlah penduduk dan berkembangnya desa ini, maka kebutuhan akan energi listrik juga meningkat. Berkembannya daerah ini menjadi tujuan pariwisata sudah tentu dijada kelestarian alam dan lingkungannya. Estetika dari pemasangan sistem instalasi juga mendapat perhatian, dimana banyak dijumpai instalasi-instalasi yang menggunakan kabel tanam untuk menyalurkan energi listrik karena alasan estetika (tidak bersliweran). Pengamatan awal di desa ini banyak dijumpai pemasangan instalasi dan penggunaan energi listrik yang masih belum memenuhi persyaratan umum instalasi listrik terutama pada masalah penggunaan, pemasangan dan sistem pengamannya.

Kecelakaan akibat penggunaan energi listrik seperti terputusnya aliran listrik, tersengat arus listrik, kebakaran dan kerusakan peralatan listrik sering terjadi di masyarakat, hal ini memicu kami untuk membuat pengabdian kepada masyarakat ini dengan tujuan agar masyarakat dapat mencegah gangguan-gangguan dan kecelakaan akibat penggunaan energi listrik tersebut. Gangguan-gangguan dan kecelakaan-kecelakaan tersebut sering disebabkan oleh Instalasi listrik yang tidak baik. Untuk gangguan-gangguan penyaluran tenaga listrik secara umum adalah pemilihan kabel dan proses penyambungan yang banyak bermasalah, dimana kabel yang seharusnya tidak boleh ditanam, masih ada yang ditanam. Isolasi Kabel tanam seharusnya menggunakan isolasi khusus yang kedap air, tetapi masih dijumpai isolasi biasa yang hanya menutupi sambungan tersebut. Untuk kecelakaan tersengat arus listrik umumnya kurangnya isolasi penghantar serta pengaman yang digunakan, sedangkan untuk kecelakan kebakaran terjadi karena hubungan pendek atau konsleting listrik, beberapa peralatan listrik yang rentan terhadap hubungan pendek seperti kabel listrik, pemakaian kabel yang tidak sesuai dengan peruntukannya menyebabkan terbakarnya lapisan pembungkus kabel. Pemasangan/penyambungan peralatan-peralatan listrik ini banyak dijumpai hal-hal yang tidak memenuhi pemasangan yang benar dan tidak sesuai dengan aturan, seperti menggunakan isolasi seadanya atau bahkan plastik yang digunakan untuk mengisolasi sambungan kabel, umur kabel yang sudah kelihatan lama dan rapuh, luas penghantar yang tidak sesuai dengan beban dari peralatan yang terpakai, pemasangan pada kotak kontak yang sangat banyak dan melebihi kapasitasnya, sehingga sangat berbahaya bagi manusia dan lingkungannya. Berdasarkan situasi diatas maka dipandang perlu untuk dilaksanakan "Pelatihan Keamanan Sistem Instalasi Kabel Tanam Di Desa Melinggih Kecamatan Payangan-Gianyar".

Rumusan masalah dalam pengabdian masyarakat ini adalah bagaimana pemasangan dam pengamanan energi listrik untuk instalasi kabel tanam yang sesuai dengan Persyaratan Umum Instalasi Listrik untuk mencegah gangguan-gangguan dan bahaya kecelakaan akibat listrik? 


\section{METODE PELAKSANAAN}

Kegiatan Pelatihan Keamanan Sistem Instalasi Kabel Tanam Di Desa Melinggih Kecamatan Payangan-Gianyar ini bertujuan untuk:

1. Memberi pemahaman kepada masyarakat tentang gangguan-gangguan instalasi listrik dan kecelakaan-kecelakaan yang diakibatkan oleh arus listrik;

2. Meningkatkan kemampuan masyarakat dalam pemasangan dan penggunaan peralatan-peralatan listrik secara benar dan aman;

3. Masyarakat mampu mencegah terjadinya gangguan-gangguan sistem kelistrikan dan kecelakaan yang disebabkan oleh aliran listrik.

Manfaat kegiatan Pelatihan Keamanan Sistem Instalasi Kabel Tanam Di Desa Melinggih Kecamatan Payangan-Gianyar ini apabila diikuti oleh peserta dengan baik, antara lain adalah sebagai berikut.

1. Masyarakat memiliki kemampuan untuk mengatasi gangguan-gangguan instalasi listrik dan mencegah kecelakaan-kecelakaan karena arus listrik;

2. Masyarakat dapat meningkatkan kemampuannya dalam memilih pengaman dan peralatanperalatan instalasi listrik yang aman;

3. Masyarakat dapat memberikan informasi ke masyarakat lainnya tentang penggunaan peralatan instalasi listrik dan mencegah jika ada yang menggunakan penyambungan peralatan instalasi listrik yang berbahaya.

Pelatihan yang diangkat dalam kegiatan pengabdian pada masyarakat ini adalah Pelatihan Pengaman Instalasi Listrik Sesuai Persyaratan Umum Instalasi Listrik 2011 Serta Amandemen 2014 Oleh karena itu diusulkan kerangka pemecahan masalah secara operasional sebagai berikut.

Penyelenggaraan pelatihan intensif tentang:

a. Pemakaian energi listrik secara aman dan benar.

1. Beda Potensial yang berbahaya bagi manusia dan lingkungannya;

2. Besarnya arus yang melewati tubuh manusia;

3. Pengaman yang digunakan untuk membatasi besarnya arus.

b. Pemasangan peralatan instalasi listrik:

1. Teknik mengidentifikasi, memilih, dan merumuskan jenis peralatan listrik yang ber SNI;

2. Teknik pemasangan peralatan instalasi listrik yang benar dan aman;

3. Pemasangan alat-alat listrik yang sesuai dengan standar;

4. Pengoperasian peralatan instalasi listrik dan alat-alat listrik.

Pelatihan yang diangkat dalam kegiatan pengabdian pada masyarakat ini adalah Pelatihan Keamanan Sistem Instalasi Kabel Tanam di Desa Melinggih Kecamatan Payangan-Gianyar. Oleh karena itu, dilaksanakan kerangka pemecahan masalah secara operasional sebagai berikut.

1. Penyelenggaraan pelatihan intensif tentang:

a. Bahaya-bahaya instalasi listrik;

b. Pemakaian energi listrik secara aman dan benar;

c. Pemilihan peralatan pengaman yang sesuai dengan peralatan yang diamankan;

d. Pemilihan kabel/Penghantar untuk penempatan pemasangan dalam instalasi listrik.

2. Implementasi Pemasangan kabel tanam untuk instalasi listrik untuk menyalurkan energi dengan benar dan aman dengan cara:

a. Teknik mengidentifikasi, memilih, dan merumuskan peralatan listrik yang akan digunakan sebagai instalasi kabel tanam;

b. Teknologi isolasi kabel/ penghantar dalam mengamankan bahaya kebocoran arus listrik;

c. Cara pemilihan Peralatan Instalasi listrik yang benar untuk digunakan dalam mengamankan peralatan dan lingkungan;

d. Teknik pemasangan dan penyambungan kabel tanam untuk instalasi daya dan penerangan;

VOLUME 17 NOMOR 1, JANUARI 2018 | 110 
e. Informasi Teknik Pelatihan Dasar Pemasangan Peralatan Instalasi listrik.

Permasalah yang utama juga adalah pengetahuan masyarakat tentang pemasangan peralatan dan instalasi listrik sangat minim/kurang, sehingga masyarakat hanya mengandalkan cara pemasangan yang tidak memenuhi standar dan yang terpenting untuk sementara adalah bisa beroperasinya peralatan-peralatan (nyala) yang memerlukan energi listrik. Begitu pentingnya energi listrik dan keterbatasan pengetahuan dasar tentang pemakaian dan pemasangan listrik menjadi penyebab utama terjadinya kegagalan instalasi listrik.

\subsection{Penghantar, Kabel dan Kawat Penghantar}

Arus Listrik adalah mengalirnya elektron secara terus menerus dan berkesinambungan pada konduktor akibat perbedaan jumlah elektron pada beberapa lokasi yang jumlah elektronnya tidak sama. satuan arus listrik adalah Ampere.

Arus listrik bergerak dari terminal positif $(+)$ ke terminal negatif (-), sedangkan aliran listrik dalam kawat logam terdiri dari aliran elektron yang bergerak dari terminal negatif (-) ke terminal positif(+), arah arus listrik dianggap berlawanan dengan arah gerakan elektron seperti ditunjukan pada gambar 2.1.

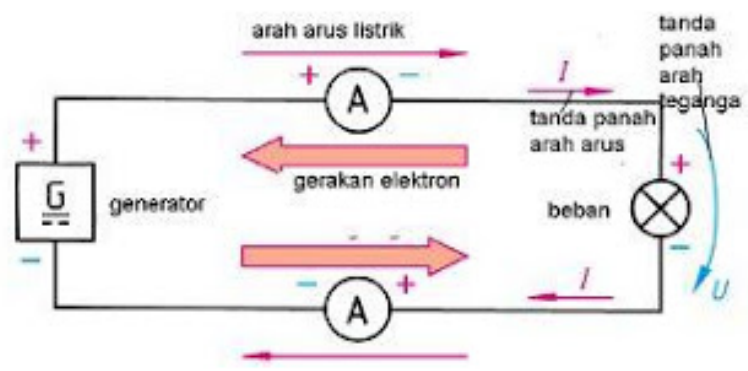

Gambar 2.1. Arah arus listrik dan pergerakan elektron

Mengalirnya arus listrik diperlukan penghantar yang mempunyai nilai hambatan yang kecil dan penempatan penghantar ini harus sesuai dengan peruntukannya, sehingga aman bagi manusia dan lingkungannya.

Kabel listrik NYA, NYM dan NYY ini merupakan tata nama atau nomenklatur pada kabel. PUIL 2011 (Persyaratan Umum Instalasi Listrik tahun 2011) dalam lampiran C dijelaskan mengenai tata nama (nomenklatur) kabel ini. Dari lampiran tersebut, kabel NYA, NYM dan NYY berarti kabel standar berpenghantar tembaga ("N") dengan isolasi dan selubung dari PVC ("Y").

\subsection{Kabel Listrik dan kuat arus listrik}

Dalam sistem instalasi listrik, untuk menghidupkan/memberi suplai daya listrik ke peralatan listrik digunakan kabel listrik. Kabel listrik adalah salah satu komponen vital yang berfungsi sebagai penghantar arus listrik dari sumber listrik menuju peralatan listrik. Kabel listrik ini seperti pembuluh darah dalam tubuh manusia, dimana bila saluran pembuluh darah ada yang bermasalah tentu tubuh tidak akan bekerja dengan baik. Kabel listrik pun demikian, bila ada saluran yang bermasalah maka akan berpotensi mengganggu sistem instalasi listrik, sehingga kabel listrik harus mendapatkan perhatian yang sangat khusus dengan suatu aturan-aturan yang sudah tertuang dalam PUIL (Persyaratan Umum Instalasi Listrik) baik dalam pemilihan, penggunaan dan pengamannnya. Kabel listrik mempunyai bahan inti penghantar dan luas penampang penghantar yang berbedabeda. Bahan penghantar dan luas penampang penghantar sangat erat hubungannya dengan dengan kapasitas penghantaran arus listriknya. Dalam istilah PUIL, besarnya kapasitas hantaran kabel dinamakan dengan Kuat Hantar Arus (KHA). 
PUIL 2011 memberikan ketentuan mengenai besarnya diameter dari penghantar kabel dan maksimum KHA terus-menerus yang diperbolehkan pada kabel tipe NYA, NYM dan NYY dan lain-lain.

\section{PELAKSANAAN KEGIATAN}

Survey awal pada sistem kelistrikan yang ada adalah sudah menggunakan kabel tanam NYY yang sudah terdapat beberapa sambungan yang bocor sehingga sering terjadi gangguan pada saat terjadi hujan. Informasi tagihan listrik juga membengkak hampir 300\% kenaikannya, ini disebabkan karena adanya arus bocor ke tanah yang nilai arusnya tidak menyebabkan putusnya MBC. Hal ini sangat merugikan dan berbahaya bagi manusia dan lingkungan karena bisa menyebabkan terkena arus listrik (kesetrum).

Dari pemantauan lapangan, kabel tanam NYY yang akan dipasang, tidak semua ditanam dalam tanah, karena pertimbangan adalah sering terjadinya kegiatan adat dimana diperlukan untuk membuat lobang dengan mencangkul dan menggunakan linggis, sehingga kemungkinan besar kabel NYY tersebut menjadi rusak. Setelah mendapat pertimbangan dengan memperhatikan segi estetika di lapangan, maka kabel induk yang juga menggunakan kabel NYY dipasang pada dinding tembok untuk memudahkan pemantauan.

Kabel NYY juga dipasang dalam tanah dengan melihat situasi lingkungan sehingga kabel tanah yang tertanan untuk lampu taman dan lampu penerangan ke bangunan-bangunan dipasang sedekat mungkin dengan pondasi atau jalan setapak.

Pengaman yang digunakan adalah MCB. Pemasangan MCB melalui kabel induk ke masing masing bangunan, jadi tujuannya adalah jika terjadi gangguan (beban lebih atau hubungan singkat) bisa segera diketahui dan dilokalisir sehingga tidak semua bangunan yang ada ikut mengalami gangguan.

Pelaksanaan kegiatan Hibah Udayana Mengabdi dengan judul Pelatihan Keamanan Sistem Instalasi Kabel Tanam Di Desa Melinggih Kecamatan Payangan-Gianyar dengan pengenalan peralatanperalatan instalasi listrik seperti kabel tanan NYY, pengaman MCB, lampu hemat energi disini menggunakan lampu LED, Lampu outdor seperti lampu taman dan lampu yang kedap air, peserta pengabdian juga dipersilahkan untuk melihat-lihat dan mempraktekkan, sehingga mereka bisa mendapatkan pemahaman yang lebih banyak tentang peralatan yang sesuai dengan standar SNILMK. Foto kegiatan dapat dilihat pada gambar 3.1 dan 3.2.
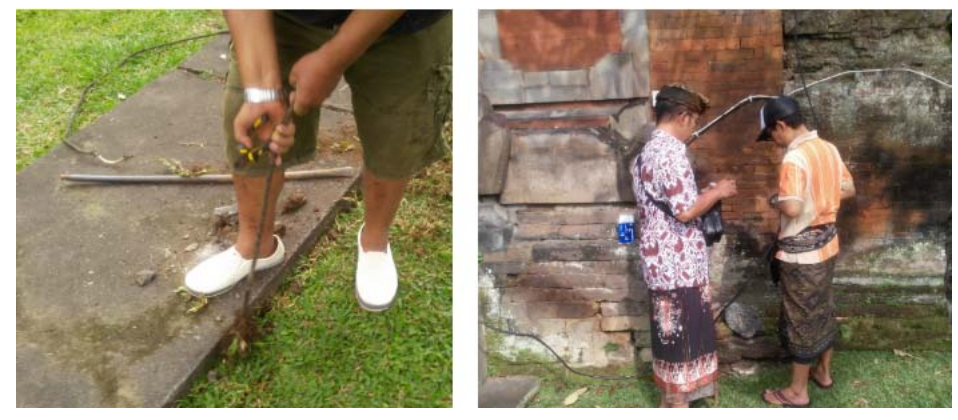

Gambar 3.1. Kabel yang terlalu banyak sambungan dan kabel NYM yang bukan untuk kabel luar 

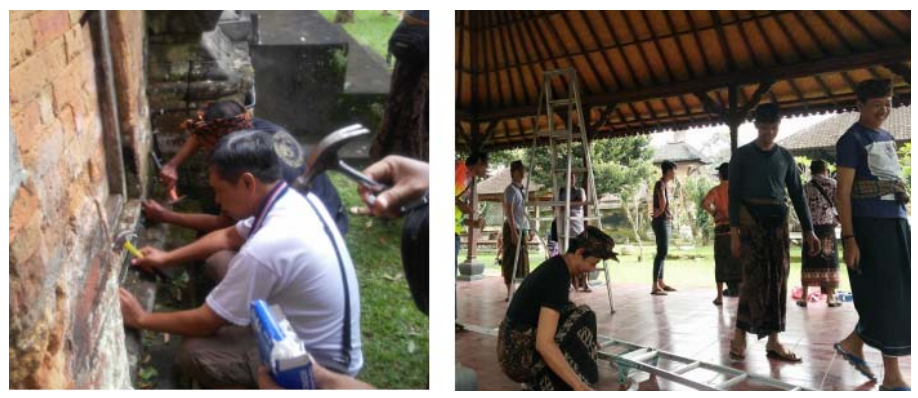

Gambar 3.2. Peserta pengabdian ikut dalam pengabdian

\section{KESIMPULAN DAN SARAN}

Simpulan yang didapat dari kegiatan pengabdian masrakat tentang Pelatihan Keamanan Sistem Instalasi Kabel Tanam Di Desa Melinggih Kecamatan Payangan-Gianyar, sebagai berikut

1. Masyarakat sudah mendapatkan ceramah, menyaksikan demontrasi tentang Dasar Pemasangan kabel tanam, sistem pengaman kabel untuk mencegah bocornya arus listrik sehingga aman bagi manusia dan lingkungannya serta terjun langsung mempraktekan di lokasi pengabdian.

2. Pemilihan bahan-bahan peralatan listrik serta cara pemasangan yang sesuai dengan Peryaratan Umum Instalasi Listrik dapat mencegah terjadinya bahaya-bahaya akibat arus listrik.

Saran yang bisa diberikan dari kegiatan pengabdian kepada masyarakat ini adalah untuk merawat dan memperbaiki jika ada terjadi kerusakan-kerusakan terhadap isolasi sambungan kabel serta isolasi kabel itu sendiri, sehingga kerugian-kerugian akibat arus listrik dapat di hindari.

\section{UCAPAN TERIMAKASIH}

Penulis mengucapkan terimakasih kepada Universitas Udayana atas dukungan yang diberikan melalui Hibah Pengabdian kepada Masyarakat Tahun 2017 dengan Surat Perjanjian Penugasan dalam Rangka Pelaksanaan Hibah Pengabdian Kepada Masyarakat Udayana Mengabdi dengan Nomor: No: 674 58/UN14.4.A/PM/2017, Tanggal 12 Juli 2017.

\section{DAFTAR PUSTAKA}

A.E. Fitzgerald,SC.D.(1983), Dasar-dasar Elektro Teknik. Northeastern University.

Badan Standarisari Nasional (2011), Persyaratan Umum Instalasi Listrik 2011 (PUIL 2011), SNI 0225:2011, Jakarta, BSN

Badan Standarisari Nasional (2014), Persyaratan Umum Instalasi Listrik 2011 (PUIL 2011), SNI 0225:2011/Amd2:2014, Amandemen 2:2014 (IEC 60364-4-42:2010, MOD), Jakarta, BSN

P. Van. Harten., E. (1983), Instalasi Listrik Arus Kuat 1, 2 dan 3 , CV Trimitra Mandiri, Jakarta 